\title{
TRANSPORT OF LIGNOHUMATE THROUGH PLANT CUTICLE - METHOD OF DIFFUSION COUPLE WITH BARRIER ON THE INTERFACE
}

\author{
${ }^{1}$ Martina KLUČÁKOVÁ, ${ }^{1}$ Marcela SMILKOVÁ, ${ }^{1}$ Petr SEDLÁČEK \\ ${ }^{1}$ Brno University of Technology, Faculty of Chemistry, Brno, Czech Republic, EU, \\ klucakova@fch.vutbr.cz
}

https://doi.org/10.37904/nanocon.2019.8467

\begin{abstract}
Agarose hydrogel was used as the transport medium for the investigation of the diffusion of lignohumate through plant cuticle. The cuticles were isolated from Prunus laurocerasus by two different methods: chemical and enzymatic. At first, the diffusion coefficient of lignohumate in agarose hydrogel was determined by means of the technique of diffusion couple: the donor part was enriched by lignohumate with homogeneous distribution on its whole volume and connected with the "pure" acceptor part without lignohumate. The diffusion coefficient was calculated on the basis of time development of diffusion flux through the interface. After that, the cuticle was placed into interface between donor and acceptor parts and the barrier ability of cuticles were characterized by the decrease in diffusion flux and the change of the concentration of lignohumate at the interface between donor and acceptor hydrogels. The transport through chemically and enzymatically cuticles as well as the abaxial (stomatous) and adaxial (astomatous) cuticles was investigated. Diffusion characteristics were determined, compared and discussed.
\end{abstract}

Keywords: Lignohumate, cuticle, agarose, diffusion, hydrogel

\section{INTRODUCTION}

Humic substances are the principal components of soil organic matter and have indispensable roles for soil and the environment in general. They play important role in plant nutrition and transport of nutrients in soils [1-3]. Nowadays, foliar fertilization and application of bio-stimulants has become a popular method for the plant nutrition and agronomy as an alternative or complement to standard root fertilizer treatments [4-7]. Transcuticular penetration into leaf tissues and sorption on the leaf surface plays a key role in the foliar application of nutrients [8-10], surfactants [11,12] and different types of pesticides [13-16].

Plant surfaces play a major role in protection against multiple potential biotic and abiotic stress factors [15,1719]. They have a protective function for undesirable penetration of harmful substances $[16,21]$ and also against water loss [20]. However, it can supress also the penetration of nutrients and bio-stimulants. Thus the main barriers for the foliar fertilization are plant cuticles and the penetrations of substances into leaves (and stems) are strongly affected by their properties [17,22].

The plant cuticle is a thin continuous layer $(<0.1-10 \mu \mathrm{m})$ of predominantly lipid material synthesised by the epidermal cells and deposited on their outer walls. The major structural model is a bilayer cuticular membrane in which the two layers are distinguishable by their ontogeny, ultrastructure and chemical composition $[20,23]$. The prevailing model considers the cuticle as a lipidic layer whose relationship with thecell wall is restricted to their adjacent position. According to this model, a cutin matrix with embedded intracuticular waxes and phenolics extends through the cuticle, while polysaccharides are restricted to the inner most cuticle region,i.e.,that in contact with the cell wall underneath. An additional layer of epicuticular waxes is deposited onto the cutin matrix and constitutes the organ-atmosphere interface [24,25].

Since the 1970s, several studies have assessed water and solute permeability and diffusion through cuticles and cutin from a wide variety of plants. In general, astomatous cuticles have a low water permeability, which 
is a thousand times lower than the plant cell wall and remains in a range comparable to that of some hydrophobic synthetic polymers [25,26]. These studies consider the cuticle and cutin as solution-diffusion membranes for water; that is, individual water molecules follow a random pathway in a mostly lipophilic environment. It has also been suggested that water transport occurs via aqueous pores or channels, whose presence seems to be highly dependent on relative humidity and temperature. The next challenge in this area will be to characterize the diffusion mechanisms that take place in the cuticle [25-27]. The transport through the cuticle is generaly considered as a diffusion controlled process consisting of three parts involving: 1) sorption into the cuticle, 2) diffusion through the cuticle, and 3) desorption from the cuticle [20].

In this work, cuticles were isolated from Prunus laurocerasus in order to study their barrier properties for lignohumate used for foliar application. The transport through the abaxial (stomatous) and adaxial (astomatous) cuticles was investigated and compared.

\section{MATERIALS AND METHODS}

Leaf cuticles were isolated by two different methods (chemical and enzymatic) as described previously $[17,28]$. In both cases, plant cuticles were isolated from Prunus laurocerasus. The isolation procedures as wrll as the main characteristics of isolated cuticles are described in detail in [17].

Agarose hydrogel (1\% wt.) was used as the transport medium for the investigation of the diffusion of lignohumat. At first, the diffusion coefficient of lignohumate in agarose hydrogel was determined by means of the technique of diffusion couple $[17,29,30]$. The donor part was enriched by lignohumate $(0,1 \%$ wt.) with homogeneous distribution on its whole volume and connected with the "pure" acceptor part without lignohumate. The preparation of agarose hydrogel and forming of lignohumate was described in [17]. In this work, the content of lignohumate was lowered in order to monitor both the concentration decrease in donor hydrogel and its increase in acceptor one. After that, the cuticle was placed into interface between donor and acceptor parts and the diffusion experiment was repeated. Both abaxial and adaxial cuticles isolated by the two different isolation methods (chemical and enzymatic) were subjected to diffusion experiments. During the diffusion experiments, all the diffusion couples were placed in a closed container above water level (to maintain constant humidity of the surroundings). Experimental conditions - in particular, relative humidity (100\%) and temperature $\left(25^{\circ} \mathrm{C}\right)$ - were held constant during the whole experimental period.

The transport of lignohumate from donor into the acceptor hydrogel was measured by a UV-VIS spectrophotometry (Varian Cary 50). At selected time intervals, the cuvettes were taken out and UV-VIS spectra of lignohumate in hydrogels were collected at given distances from the interface. The measurement of UV-VIS absorbance at different distances from the interface was performed by means of a special in-house made accessory providing controlled fine vertical movement of the cuvette in the spectrophotometer [17,31].

\section{RESULTS AND DISCUSSION}

In general, if the diffusion couple was formed without a cuticle and both donor and acceptor hydrogel had the same structure, the concentration of lignohumate at the interface should be constant and equal to the half of its initial concentration in donor hydrogel $[29,30]$. We can see that this presumption was confirmed in this work (Figure 1). Experimental data were fitted by the concentration profile calculated according to the following mathematical model. In this work, the diffusion coefficient was calculated on the basis of time development of diffusion flux through the interface. The mathematical model was based based on Fick's equation describing one-dimensional non-stationary diffusion

$$
\frac{\partial c}{d t}=D_{e f} \frac{\partial^{2} c}{\partial x^{2}}
$$


where $c$ represents the concentration of the diffusing compound in the time $t$ and the position $x$ (the coordinate parallel to the direction of diffusion movement). Diffusion coefficient $D_{e f}$ is the main parameter characterizing rate of the diffusion process. It is the so called "effective diffusion coefficient" in which the tortuous movement of the diffusing particles in the porous structure of hydrogel is involved. While solving this partial differential equation (1), appropriate initial and boundary conditions must be applied according to the particular experimental settings $[29,30]$.

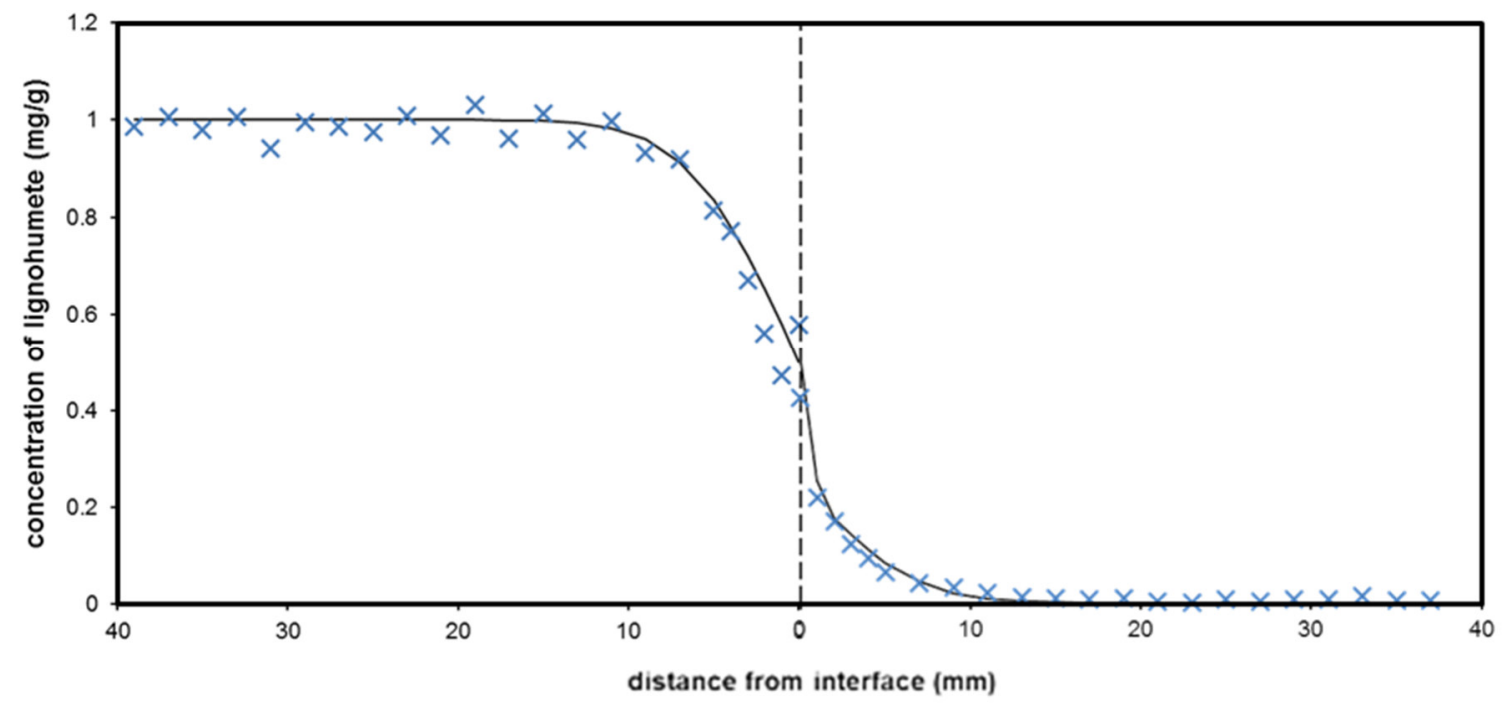

Figure 1 The concentration profile of lignohumate in the diffusion couple without cuticle after 1 day. Experimental data are fitted by equation (4).

Mathematical description of diffusion in the diffusion couple without cuticle is relatively easy. Before the start of diffusion, the donor hydrogel has a constant concentration of lignohumate $\left(c_{0}\right)$ along the whole length whereas its concentration in the acceptor hydrogel is zero; therefore the initial conditions are

$c=c_{0}, \quad x<0, \quad t=0$

$c=0, \quad x>0, \quad t=0$

and the solution of the second Fick (1) is

$c(x, t)=\frac{1}{2} c_{0} \operatorname{erfc} \frac{x}{\sqrt{4 D_{\text {ef }} t}}$

It can be seen that concentration of diffused component on the interface is time independent and equal to $c_{0} / 2$. Total diffusion flux $m_{t}$ which goes through the interface between donor and acceptor hydrogels $(x=0)$ in time $t$ can be calculated as $[29,30]$.

$m_{\mathrm{t}}=c_{0} \sqrt{\frac{D_{\mathrm{ef}, \mathrm{A}} t}{\pi}}$

One of the boundary conditions is that the concentration of lignohumate remains equal to zero for $x \rightarrow \infty$, it means "at the end of acceptor hydrogel". At we can see in Figure 2, experimental data did not comply with 
this condition for longer duration of experiment. It resulted in the "curving" of the dependence of $m_{t}$ on $\sqrt{ } t$. Therefore, only the linear parts of the obtained dependencies were fitted by equation (5).
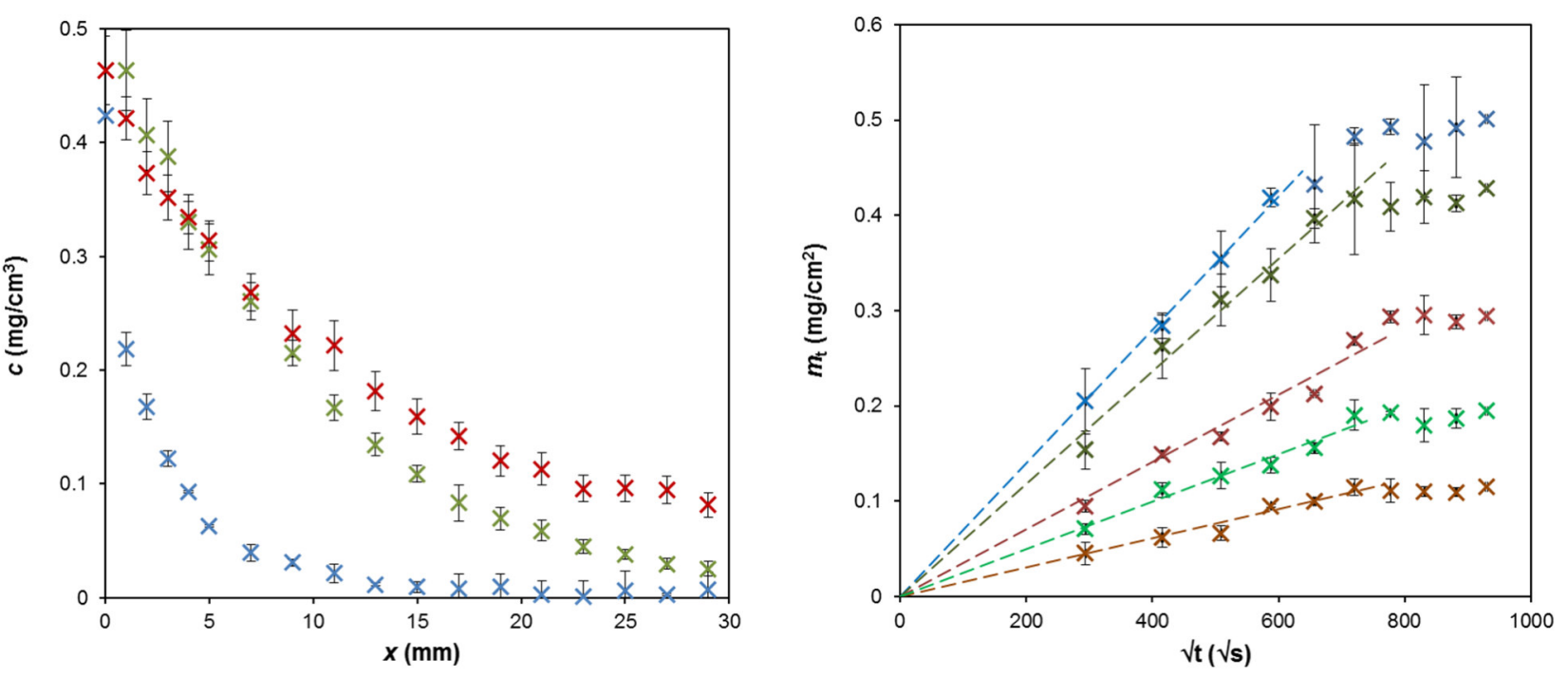

Figure 2 The concentration profiles of lignohumate for the acceptor hydrogel in the couple without cuticle after 1 (blue), 4 (khaki), and 6 (red) days - left; experimental data fitted by equation (4) for the diffusion couple withou cuticle (blue), with the stomatous chemically isolated (khaki), stomatous enzymatically isolated

(red), astomatous chemically isolated (green), and astomatous enzymatically isolated (orange) - right.

Table 1 Concentrations of initial solutions used to prepare hydrogels

\begin{tabular}{|c|c|c|c|c|}
\hline ratio & $\begin{array}{c}\text { stomatous } \\
\text { chemically isolated }\end{array}$ & $\begin{array}{c}\text { stomatous } \\
\text { enzymatically isolated }\end{array}$ & $\begin{array}{c}\text { astomatous } \\
\text { chemically isolated }\end{array}$ & $\begin{array}{c}\text { astomatous } \\
\text { enzymatically isolated }\end{array}$ \\
\hline$c / c_{a}$ & $0.84 \pm 0.05$ & $0.50 \pm 0.03$ & $0.36 \pm 0.02$ & $0.22 \pm 0.01$ \\
\hline$m / m_{a}$ & $0.85 \pm 0.05$ & $0.54 \pm 0.03$ & $0.37 \pm 0.02$ & $0.22 \pm 0.01$ \\
\hline
\end{tabular}

The effective diffusion coefficient of lignohumate in agarose hydrogel was determined as $(1.54 \pm 0.09) \times 10^{-10}$ $\mathrm{m}^{2} / \mathrm{s}$. This value was the same for all diffusion experiments (including experiments with cuticles), because $D_{\text {ef }}$ characterize the transport in the hydrogel. The barrier properties of cuticles can be characterized by observed decreases in measured diffusion fluxes (see also Figure 2) and changes in the concentration of lignohumate at the interface. If we index the quantities valid for experiment without cuticle $c_{a}$ and $m_{a}$, we can express the barrier ability of cuticle as the average ratios between concentrations at interface and total diffusion fluxes from donor into acceptor hydrogels as $c / c_{a}$ and $m / m_{a}$, respectively. The calculated ratios are listed in Table 1 . We can see that the presence of cuticle at interface between donor and acceptor hydrogels can reduce the diffusion flux as well as the concentration at interface for all used cuticles. The barrier ability decreased in the following order: stomatous chemically isolated $>$ stomatous enzymatically isolated $>$ astomatous chemically isolated $>$ astomatous enzymatically isolated. The decrease was between 15 and $88 \%$. The highest barrier ability had the astomatous enzimatically isolated cuticle, the lowest stomatous chemically isolated one.

\section{CONCLUSION}

In this work, the barrier ability of cuticles isolated from Prunus laurocerasus by two different methods (chemical and enzymatic) was investigated. Lignohumate was used as an bio-stimulant for foliar application was used as diffusant. Agarose hydrogel was used as the transport medium for the diffusion couple formed by donor hydrogel enriched by lignohumate and initially pure acceptor hydrogel. The diffusion coefficient was calculated 
on the basis of time development of diffusion flux through the interface between both hydrogels. In following experiments, the cuticle was placed into interface between donor and acceptor parts and the barrier ability of cuticles were characterized by the decrease in diffusion flux and the concentration of lignohumate at the interface between donor and acceptor hydrogels. The highest barrier ability had the astomatous enzimatically isolated cuticle, the lowest stomatous chemically isolated one. Stomata due their relatively high sizes 12-14 $\mu \mathrm{m}$ [17] can support the transport of lignohumate which resulted in higher diffusion fluxes. Chemical isolation, used in this work, was probablz less suitable because of partial damage of cuticle resulting in the decrease in its barrier ability.

\section{REFERENCES}

[1] KLUČÁKOVÁ, M. and KALINA, M. Composition, particle size, charge and colloidal stability of pH-fractionated humic acids. Journal of Soils and Sediments 2015. vol. 15, iss. 9, pp. 1900-1908.

[2] KLUČÁKOVÁ, M. and NOVÁČKOVÁ, K. Comparison of Thermal and Chemical Stability of Cu-humic Complexes. Journal of Soils and Sediments 2014, Vol. 14, No. 2, p. 360-367.

[3] KLUČÁKOVÁ, M. Complexation of metal ions with solid humic acids, humic colloidal solutions, and humic hydrogel. Environmental Engineering Science 2014. vol. 31, iss. 11, pp. 612-620.

[4] NESHEV, N. and MANOLOV, I. Content and uptake of nutrients with plant biomass of potatoes depending on potassium fertilization. Agriculture and Agricultural Science Procedia 2015. vol. 6, iss. 1, pp. 63-66.

[5] PEIGNE, J., VIAN, J.F., PAYET, V. and SABY, N.P.A. Soil fertility after 10 years of conservation tillage in organic farming. Soil and Tillage Research 2018. vol. 175, iss. 1, pp. 194-204.

[6] OKUDA, A., KAWASAKI, T. and YAMADA, Y. Foliar absorption of nutrients. Soil Science and Plant Nutrition 1960. vol. 6, iss. 2, pp. 66-70.

[7] FERNANDEZ, V. and EICHERT, T. Uptake of hydrophilic solutes through plant leaves: current state of knowledge and perspectives of foliar fertilization. Critical Reviews in Plant Sciences 2009. vol. 28, iss. 1-2, pp. 36-68.

[8] FAGERIA, N.K., BARBOSA, F.M.P., MOREIRA, A. and GUIMARAES, C.M. Foliar fertilization of crop plants. Journal of Plant Nutrition 2009. vol. 32, iss. 6, pp. 1044-1064.

[9] MANDIC, V. SIMIC, A., KRNJAJA, Z., BIJELIC, Z., TOMIC, A., STANOJKOVIC, D. and RUZIC, M.D. Effect of foliar fertilization on soybean grain yield. Biotechnology in Animal Husbandry 2015. vol. 31, iss. 1, pp. 133-143.

[10] LI, M., WANG, S., TIAN, X., LI, S., CHEN, Y, JIA, Z., LIU, K. and ZHAI, A. Zinc and iron concentrations in grain milling fractions through combined foliar applications of $\mathrm{Zn}$ and macronutrients. Field Crops Research 2016. vol. 187 , iss. 1 , pp. 135-141.

[11] CHAMEL, A. and GAMBONNET, B. Sorption and diffusion of an ethoxylated stearic alcohol and an ethoxylated stearic amine into and through isolated plant cuticles. Chemosphere 1997. vol. 34, iss. 8, pp. 1777-1786.

[12] LIU, H., SHAO, B., LONG., X. YAO, Y. and MENG, Q. Foliar penetration enhanced by biosurfactant rhamnolipid. Colloids and Surfaces $B$ 2016. vol. 145, iss. 1, pp. 548-554.

[13] WANG, C.J. and LIU, Z.Q. Foliar uptake of pesticides - present status and future challenge. Pesticide Biochemistry and Physiology 2007. vol. 87, iss. 1, pp. 1-8.

[14] ZELENÁ, V. and VEVERKA, K. Effect of surfactants and liquid fertilizers on transcuticular penetration of fungicides. Plant Protection Science 2007. vol. 43, iss. 4, pp. 151-156.

[15] KHAYET, M. and FERNANDEZ, V. Estimation of the solubility parameters of model plant surfaces and agrochemicals: a valuable tool for understanding plant surface interactions. Theoretical Biology and Medical Modelling 2012. vol. 9, iss. 1, pp. 45-66.

[16] KHORRAM, M.S., ZHANG, Q., LIN, D., ZHENG, Y., FANG, H. and YU, Y. Biochar: a review of its impact on pesticide behavior in soil environments and its potential applications. Journal of Environmental Sciences 2016. vol. 44, iss. 1, pp. 269-279.

[17] SMILKOVÁ, M., SMILEK, J., KALINA, M., SEDLÁČEK, P., PEKAŘ, M. and KLUČÁKOVÁ, M. A simple technique for assessing of the cuticular diffusion of humic acid biostimulants. Plant Methods 2019. vol. 15, iss. 1, pp. 83-93. 
[18] ZHANG, J., FAN, S-k., ZHANG, M-h., GRIENEISEN, M.L. and ZHANG, J-f. Aliphatic hydrocarbons recovered in vegetables from soils based on their in-situ distribution in various soil humus fractions using a successive extraction method. Journal of Hazardous Materials 2018. vol. 346, iss. 1, pp. 10-18.

[19] KULIKOVA, N.A., BADUN, G.A., KOROBKOV, V.I., CHERNYSHEVA, M.G., TSVETKOVA, E.A., ABROSKIN, D.P., KONSTANTINOV, A.I., ZAITCHIK, B.T., RUZHITSKY, A.O. and PERMINOVA, I.V. Accumulation of coal humic acids by wheat seedlings: Direct evidence using tritium autoradiography and occurrence in lipid fraction. Journal of Plant Nutrition and Soil Science 2014. vol. 177, iss. 1, pp. 875-883.

[20] KIRKWOOD, R.C. Recent developments in our understanding of the plant cuticle as a barrier to the foliar uptake of pesticides. Pesticide Science 1999. vol. 55, iss. 1, pp. 69-77.

[21] RIEDERER, M. and SCHREIBER, L. Protecting against water loss: analysis of the barrier properties of plant cuticles. Journal of Experimental Botany 2001. vol. 52, iss. 363, pp. 2023-2032.

[22] HEREDIA, A. Biophysical and biochemical characteristics of cutin, a plant barrier biopolymer. Biochimica et Biophysica Acta (BBA) - General Subjects 2003. vol.1620, iss. 1-3, pp. 1-7.

[23] HOLLOWAY, P.J. Structure and chemistry of plant cuticles. Pesticide Science 1993. vol. 37:203-232 (1993).

[24] FERNANDEZ, V., GUZMÁN-DELGADO, P., GRACA, J. SANTOS, S. and GIL, L. Cuticle structure in relation to chemical composition: re-assessing thep Model. Frontiers in Plant Science 2016. vol. 7, iss. 1, p. 427-440.

[25] DOMINGUEZ, E., HEREDIA-GUERRERO, J.A. and HEREDIA, A. The biophysical design of plant cuticles: an overview. New Phytologist 2011, vol. 189, iss. 1, 938-949.

[26] FERNÁNDEZ, V, and EICHERT, T. Uptake of hydrophilic solutes through plant leaves: current state of knowledge and perspectives of foliar fertilization. Critical Reviews in Plant Sciences 2009. vol. 28, iss. 1, pp. 36-68.

[27] KERSTIENS, G. Parameterization, comparison, and validation of models quantifying relative change of cuticular permeability with physicochemical properties of diffusants. Journal of Experimental Botany 2006. vol. 57, iss. 11, pp. 2525-2533.

[28] SOLEL, Y. and EDGINGTON, L.V. Transcuticular movement of fungicides. Phytopathology 1972. vol. 63, iss. 1, pp. 505-510.

[29] KLUČÁKOVÁ, M. and PEKAŘ, M. Transport of copper(II) lons in humic gel - new results from diffusion couple. Colloids and Surfaces A. 2009. vol. 349, iss. 1-3, pp. 96-101.

[30] KLUČÁKOVÁ, M., KALINA, M., SMILEK, J. and LAŠTU゚VKOVÁ, M. The transport of metal ions in hydrogels containing humic acids as active complexation agent. Colloids and Surfaces A. 2018. vol. 557, iss. 1, pp. 116122.

[31] SEDLÁČEK, P., SMILEK, J. and KLUČÁKOVÁ, M. How the interactions with humic acids affect the mobility of ionic dyes in hydrogels - 2. Non-stationary diffusion experiments. Reactive and Functional Polymers 2014. vol. 75, iss. 1 , pp. 41-50. 